\title{
O EL ASILO CONTRA LA OPRESIÓN: EL CASO DE LOS EXILIADOS CHILENOS QUE SE ASENTARON EN LA CIUDAD DE MALMÖ (SUECIA)
}

\author{
Or asylum against oppression: \\ the case of Chilean exiles who settled in the city of Malmö (Sweden)
}

José Berrios-Riquelme*

Carlos Piñones Rivera**

Carla Vidal Figueroa***

\begin{abstract}
Resumen. La dictadura militar que vivió Chile entre los años 1973 y 1990 persiguió punitivamente a sus detractores, motivo por el que miles de personas tuvieron que abandonar el país para proteger su integridad. Entre los distintos destinos escogidos por la diáspora, Suecia fue una sociedad hospitalaria por el contexto social y político imperante. El presente artículo describe cómo un grupo de refugiados chilenos vivió su exilio en la ciudad de Malmö. El principal hallazgo es que la identidad de estas personas tuvo una reconstrucción colectiva como inmigrantes políticos luego de que la dictadura militar llegara a su fin. En la discusión se considera la literatura existente sobre chilenos exiliados en Europa y se realizan sugerencias para futuras investigaciones.
\end{abstract}

Palabras clave: exilio; Chile; Suecia; refugiados; inmigrantes políticos.

Abstract. The military dictatorship lived in Chile between 1973 and 1990 punitively chased its detractors, reason why thousands of people had to abandon the country to protect their integrity. Between the different destinations selected by the diáspora, Sweden was a hospitable society because of the social and political prevailing context. The following article describes how a group of Chilean refugees lived their exile at the city of Malmö. The main finding is that the identity of these people had a collective reconstruction as political immigrants after the military dictatorship had come to an end. At the discussion, existing literature about Chilean exiled in Europe is regarded and suggestions are made for future research.

Keywords: exile; Chile; Sweden; refugees; political immigrants.

Instructor del Departamento de Ciencias Sociales, Universidad de Tarapacá, Chile. Iquique, Tarapacá, Chile. E-mail: jberrios@uta.cl. Orcid: 0000-0003-2947-4739.

** Investigador Asociado al Instituto de Estudios Internacionales, Universidad Arturo Prat, Chile. Iquique, Tarapacá, Chile. E-mail: carpinon@unap.cl. Orcid: 0000-0002-4771-3345.

*** Profesora Asistente del Departamento de Trabajo Social, Universidad de Concepción. Concepción, Biobío, Chile. E-mail: carvidal@udec.cl. Orcid: 0000-0002-6471-135X. 


\section{Introducción}

A primera hora de la mañana del 11 de septiembre de 1973, dos aviones F118 cruzaron la capital chilena con el objetivo de atacar el palacio de la Moneda. A las 10:03 horas dejaron caer cinco bombas que daban fin al Gobierno del Presidente Salvador Allende. Este acto concretaba meses de tensiones políticas derivadas del contexto socioeconómico de Chile y a la vez, dio el inicio a una serie de hechos que atentaron contra los derechos humanos de chilenos y chilenas, tales como la toma de prisioneros que sufrieron torturas en campos de concentración, personas que fueron fusiladas o desaparecidas y otras que tuvieron que abandonar el país por motivos de seguridad personal. Cuando se retornó a la democracia en Chile se crearon instancias para investigar sobre los crímenes de lesa humanidad ocurridos en la dictadura, tales como el Informe Rettig o la Comisión Valech, no obstante, es insólito que el exilio sea la violación a los DDHH que menos se ha estudiado (Pinto, 2012). De hecho, cuando se conmemoró el trigésimo aniversario del Golpe de Estado, el exilio no fue considerado en los seminarios, debates y mesas redondas (Rebolledo, 2006). Extraña que desde el Estado no exista un interés por abordar la realidad de las personas que tuvieron que partir al exilio porque su vida corría peligro por ser adherentes o simpatizantes a la política del Gobierno derrocado. Es como si este desplazamiento forzado de personas no hubiese estado determinado por la dictadura militar. Esta realidad encontraría su explicación porque cuando se volvió a la democracia, el país estaba fraccionado social y políticamente, además, el interés del Estado se centró en investigar los crímenes de lesa humanidad cometidos por la dictadura militar. Junto con esto, también contribuyó la imagen del "exilio dorado" que construyó la dictadura sobre los chilenos que tuvieron un buen pasar en el extranjero.

El exilio que comenzó en septiembre de 1973 y que continuó durante largos años, fue el éxodo más grande de chilenos conocido hasta el día de hoy. Este fenómeno propiciado por la dictadura, tuvo el objetivo de debilitar a un sector político del país que estaba fuertemente comprometido con un cambio social (Pinto, 2012). Aunque no se conoce exactamente el número de personas que debieron partir al exilio, se estima que fueron entre 500.000 y 1.000 .000 los chilenos que tuvieron que dejar el país entre 1973 y 1989 (García, 2013). La búsqueda de refugio se desplegó por distintas partes del mundo, privilegiando aquellos países que detentaban gobiernos situados a la izquierda del espectro político. Las estadísticas censales indican que muchos exiliados retornaron al país, así como otros decidieron quedarse en la sociedad que los acogió durante esos momentos difíciles (Martínez et alii, 2013). Aunque no hay investigaciones que presenten cifras oficiales sobre los chilenos residentes en los países a los que llegaron como refugiados, la bibliografía señala que los 
principales destinos fueron Suecia, Australia y Francia (Camacho, 2015). En el presente Suecia es uno de los países que todavía tiene una gran población de chilenos que llegaron como refugiados políticos, así como la comunidad chilena más numerosa de Europa y la tercera colonia chilena más grande en el mundo después de Argentina y Estados Unidos (INE, DICEOEX, 2015). A pesar de contar con esta información, son escasas las investigaciones sobre los exiliados chilenos en Suecia y las pocas que hay, se han realizado desde la academia sueca con personas que no hablan castellano, restringiendo el análisis e interpretación de los hechos (Camacho, 2011).

En lo vivido por estas personas que tuvieron que dejar de manera forzada su país natal, destaca un proceso de construcción y reconstrucción identitaria, lo que en la presente investigación tuvo su auge durante el desarrollo del post-exilio. Para comprender este análisis, la identidad se concibe como una construcción social y dinámica en la que los actores sociales utilizan diferentes estrategias de negociación para su constante construcción y reconstrucción social (Mungoi, 2012). En el caso de los refugiados, la literatura sobre la reconstrucción de su identidad ha establecido que ésta se vincula estrechamente con los mecanismos de supervivencia utilizados. En este sentido, la identidad actúa como un punto de enraizamiento desde el cual los individuos toman decisiones respecto a su vida en el país de acogida (Mosselson, 2006). Por lo tanto, se entiende que la construcción de la identidad es un proceso dinámico, sobre todo cuando existen dos contextos de referencia que influyen en su continua reconstrucción (Soriano-Miras, 2008). Lo anterior se refleja en el presente documento, donde se exponen los relatos de refugiados chilenos que llegaron a Suecia en la década de 1970 y que fueron moldeando su identidad en el país de acogida según los sucesos sociales y políticos que se desarrollaban en Chile.

Considerando lo expuesto, el objetivo del presente manuscrito es conocer cómo vivieron las etapas del exilio un grupo de refugiados chilenos en Suecia. Para alcanzar este objetivo se realizaron 13 entrevistas en la primavera escandinava del año 2013 en la ciudad de Malmö, Suecia. Para que alguien fuera escogido como participante, el criterio de inclusión fue que la persona tuviera nacionalidad chilena y el estatus de refugiado político durante la década de 1970. Para tomar contacto con las personas se utilizó la técnica bola de nieve entre los residentes chilenos en la ciudad de Malmö. Las entrevistas fueron en profundidad, en lengua castellana y llevadas a cabo por la misma persona. Todos los participantes decidieron dar su testimonio de manera voluntaria y sin ninguna retribución a cambio. El foco de las entrevistas estuvo destinado a indagar sobre su adaptación en Suecia y cómo vivieron el exilio en sus distintas etapas. Antes de iniciar las entrevistas se solicitó el consentimiento verbal para grabar, posteriormente se transcribió la información, codificando 
los datos con ayuda del software NVIVO y se interpretaron desde una perspectiva interaccionista. Para resguardar el anonimato de los participantes se citan los relatos por el número ordinal en el que se realizaron las entrevistas, sin embargo, en la tabla 1 se presentan algunos de sus datos sociodemográficos para ayudar a entender los fragmentos de las entrevistas que se citan.

Tabla 1. Caracterización de los participantes

\begin{tabular}{|c|c|c|c|c|c|}
\hline $\begin{array}{c}\text { Personas } \\
\text { entrevistadas }\end{array}$ & Género & $\begin{array}{c}\text { Edad que tenía } \\
\text { cuando llegó a } \\
\text { Suecia }\end{array}$ & $\begin{array}{c}\text { Estado civil } \\
\text { cuando llegó a } \\
\text { Suecia }\end{array}$ & $\begin{array}{l}\text { A Suecia } \\
\text { llegó con: }\end{array}$ & $\begin{array}{c}\text { Edad al } \\
\text { momento de la } \\
\text { entrevista (2013) }\end{array}$ \\
\hline $\begin{array}{l}\text { Primera } \\
\text { participante }\end{array}$ & $\mathrm{F}$ & 32 & Casada & $\begin{array}{c}\text { Esposo e } \\
\text { hijos }\end{array}$ & 71 \\
\hline $\begin{array}{l}\text { Segundo } \\
\text { participante }\end{array}$ & M & 20 & Soltero & Solo & 58 \\
\hline $\begin{array}{l}\text { Tercer } \\
\text { participante }\end{array}$ & $M$ & 31 & Casado & Esposa e hijos & 67 \\
\hline $\begin{array}{l}\text { Cuarta } \\
\text { participante }\end{array}$ & $\mathrm{F}$ & 34 & Casada & $\begin{array}{c}\text { Esposo e } \\
\text { hijos }\end{array}$ & 69 \\
\hline $\begin{array}{l}\text { Quinto } \\
\text { participante }\end{array}$ & M & $S / I$ & Casado & Solo & $S / I$ \\
\hline $\begin{array}{l}\text { Sexto } \\
\text { participante }\end{array}$ & M & 20 & Soltero & Solo & 57 \\
\hline $\begin{array}{l}\text { Séptima } \\
\text { participante }\end{array}$ & $\mathrm{F}$ & $S / I$ & $S / I$ & $S / I$ & $S / I$ \\
\hline $\begin{array}{l}\text { Octavo } \\
\text { participante }\end{array}$ & $M$ & 31 & Casado & Esposa & 65 \\
\hline $\begin{array}{l}\text { Novena } \\
\text { participante }\end{array}$ & $\mathrm{F}$ & 21 & Soltera & Sola & 56 \\
\hline $\begin{array}{l}\text { Décimo } \\
\text { participante }\end{array}$ & $M$ & $S / I$ & $S / I$ & $\mathrm{~S} / \mathrm{I}$ & $S / I$ \\
\hline $\begin{array}{l}\text { Undécimo } \\
\text { participante }\end{array}$ & M & 33 & Casado & Esposa e hijos & 71 \\
\hline $\begin{array}{l}\text { Duodécima } \\
\text { participante }\end{array}$ & $F$ & 34 & Casada & Esposo & 68 \\
\hline $\begin{array}{l}\text { Decimotercer } \\
\text { participante }\end{array}$ & $M$ & $S / I$ & Casado & Esposa e hijos & $S / I$ \\
\hline
\end{tabular}

Fuente: Elaboración propia con base en las entrevistas.

El presente manuscrito se divide en cinco secciones. En el primer apartado se introduce el fenómeno a estudiar. En la segunda parte se describe el contexto sueco de la década de 1970 que propició la llegada de los exiliados chilenos. En el tercer segmento se analiza cómo los refugiados chilenos se adentraron en el exilio en Suecia. En la cuarta sección se trabajan las categorías relacionadas con la identidad desarrollada de estas personas en el post-exilio. Finalmente, 
en el quinto apartado se discuten los resultados y se realizan sugerencias para futuras investigaciones en el área.

\section{El contexto sociopolítico sueco en la década de $\mathbf{1 9 7 0}$}

Suecia está ubicado al norte de Europa, su geografía y clima durante mucho tiempo hicieron que no fuera llamativo para personas de otras latitudes, sin embargo, este país se transformó en una sociedad receptora de inmigrantes desde la depresión de 1930. Desde esta fecha su población inmigrante siguió creciendo sostenidamente, incrementándose considerablemente por el alto número de refugiados que huían de la Segunda Guerra Mundial (Bengtsson et alii, 2005). Al iniciar la década de 1950, Suecia emergía con un alto nivel de calidad de vida para sus ciudadanos, determinada principalmente por su estabilidad social, económica y política. Este contexto constituyó un factor atrayente para todas las personas que deseaban iniciar una nueva vida luego de la polarización política que tuvo Europa y que trajo consigo su reestructuración territorial. Esta realidad Ilevó a que Suecia aumentara su atractivo como sociedad receptora de inmigración laboral, pero como no pudo estar ajena al contexto de sus países vecinos, cayó en una recesión que alcanzó su auge en los años 1966 y 1967. La crisis económica motivó que el Gobierno tomara varias medidas para mitigar los efectos socioeconómicos, entre ellas, la promulgación en 1968 de una ley migratoria restrictiva que regulaba la inmigración no nórdica, pero que contenía algunas excepciones sobre la entrada de refugiados y su reunificación familiar (Bengtsson et alii, 2005). Esta ley contenía un plan de integración especial para la adaptación de los nuevos inmigrantes en Suecia, destacando la enseñanza del idioma nativo en las escuelas públicas, la organización sobre el patrón cultural sueco, la enseñanza del idioma sueco durante las horas de trabajo y sin descontar dinero de las remuneraciones, entre otras medidas (Montesino, 2017). Este período, en el que se buscaba integrar a los inmigrantes en la sociedad sueca y en el mercado laboral, fue liderado por una política socialdemócrata con una clara y acogedora política de refugio, convirtiendo a Suecia en un destino preferente para las personas que se veían obligadas a dejar su país natal por miedo a perder su vida. Otro aspecto a destacar, es que al iniciar la década de 1970 el primer ministro de Suecia era Olof Palme, para quien las relaciones internacionales se convirtieron en una cuestión central de su gestión. En esta línea, Palme tomó posición en contra de la guerra de Vietnam, el Apartheid en Sudáfrica, la invasión a Checoslovaquia, la dictadura de Franco en España y posteriormente, el golpe de Estado en Chile (Doorn, 2012). De esta manera, desde 1970 Suecia contaba con un contexto social, político y económico que lo llevó a ser reconocido como un destino propicio para ciudadanos de otras nacionalidades que buscaban asilo. Es así como a inicio de esta década llega a Suecia un gran contingente de 
latinoamericanos que buscaban huir de las dictaduras militares imperantes en sus países, destacando Chile, Argentina, Brasil y Bolivia. En el caso de Chile, fueron varios los factores que propiciaron la llegada de estos refugiados según explica Camacho (2015, p. 232):

Una serie de coincidencias, tanto temporales como espaciales, fueron la base de la enorme solidaridad que Suecia mostró a Chile. Las causas que dieron impulso a la singular simpatía mostrada por Suecia son: la permanencia de Olof Palme en el cargo de primer ministro; la representación de Suecia en Chile en la persona de Harald Edelstam; la existencia del Chilekommittén y de un histórico movimiento de solidaridad con los procesos de liberación y autodeterminación; los lazos entre el Partido Social Demócrata y el Partido Radical y otros dirigentes políticos de la Unidad Popular; la imagen fascista que transmitía la Junta Militar en los primeros años, y que recordaba el levantamiento franquista de España en 1936, en el que lucharon más de medio millar de suecos como soldados de las Brigadas Internacionales; la existencia de redes de contacto establecidas a través de los acuerdos firmados de ayuda al desarrollo.... y el hecho de que Suecia fuera uno de los países más desarrollados del planeta en ese momento y contara con fondos económicos que podían ser empleados en la ayuda humanitaria y los comités de solidaridad.

El Gobierno socialdemócrata de Olof Palme empezó a ayudar económicamente al Gobierno de la Unidad Popular en 1971 y ya para agosto de 1973, había hecho de Chile uno de sus países prioritarios para la cooperación internacional (Camacho, 2011). Para el 11 de septiembre de 1973, fecha en que se ejecutó la toma de poder por parte de las fuerzas armadas, los lazos entre Chile y Suecia ya estaban consolidados, razón por la que no extraña el alto número de chilenos que escogió ese destino para solicitar asilo. Junto con esto, durante los primeros meses de la dictadura en Chile fue importante la figura del Embajador sueco Harald Edelstam, quien luego del Golpe Militar adoptó una postura activista y denunciadora para gestionar el asilo de chilenos y otros latinoamericanos perseguidos por la dictadura (Camacho, 2011). En Suecia, la grave represión sufrida por los chilenos en los primeros años de la dictadura despertó un fuerte movimiento de solidaridad y rechazo explícito a la misma desde la ciudadanía. Esto se debió, en gran parte, a que un alto número de chilenos llegaron a Suecia con secuelas físicas y mentales producto de la tortura recibida, por lo que el pueblo sueco materializó su repudio a través de una amplia movilización social de manifestaciones mediáticas y políticas contra la dictadura chilena y su violación a los derechos humanos (Camacho, 2015). Este contexto generó un ambiente propicio donde los chilenos y chilenas llegaron como héroes que habían luchado contra el capitalismo. Además, esta cercanía hizo que los refugiados que llegaban se sintieran acogidos en un ambiente donde eran recibidos y legitimados por su pensamiento político. 
La dictadura militar duró casi 17 años y durante este período, los refugiados chilenos tuvieron que adaptarse no sólo a la sociedad sueca, sino también a un proceso identitario y de lucha que estuvo determinado por la forma en que vivieron su exilio.

\section{El exilio}

El período del exilio está comprendido entre el año 1973 y el fin de la dictadura militar en el año 1990. Para describir la experiencia de los chilenos que llegaron a Suecia, el exilio será entendido como el abandono de su país dentro de un contexto de violencia política y de la búsqueda de refugio en otra sociedad por un tiempo no determinado (Bolzman, 1996). Esta realidad que en un comienzo estaba pensada como provisoria y a corto plazo, se convirtió en un estado permanente y marcado por rupturas en la vida cotidiana de personas que añoraban retornar a su tierra natal (Bolzman, 1993). Cuando los exiliados Ilegaban a Suecia, era con un convencimiento de que su estadía sería breve y visualizaban que el tiempo a vivir ahí estaría destinado para apoyar la causa en Chile a la distancia. Esta idea llevó a que durante los primeros años del exilio vivieran con "las maletas hechas", es decir, pensando constantemente en el retorno y preparándose para cualquier indicio que permitiera esta acción (Camacho, 2011). De esta manera, en la primera categoría del exilio se encuentra la adaptación en Suecia, la cual da cuenta de cómo fue el proceso de inserción de estas personas en la sociedad de acogida y que será abordado a continuación.

\section{a) Adaptándose al exilio en Suecia}

Durante la década de 1970 una gran cantidad de refugiados chilenos Ilegaron a Suecia por temas humanitarios y eran acomodados en campamentos especialmente diseñados para su correcta acogida. En estas instalaciones recibían atenciones médicas y psicológicas, así como clases donde se les enseñaba la cultura sueca, destacando la enseñanza del idioma y la preparación para el mundo laboral. Al transcurrir un par de meses, estas personas se insertaban en la sociedad sueca y recibían la ayuda que otorgaba ese Estado Social Demócrata. Respecto a esto, el segundo participante comenta:

Aquí en Suecia no había esa angustia de decir shuuu llegó el fin de mes y no había para pagar la luz. Si estabas realmente mal podías ir a la oficina social y mostrar lo que te habían dado y los gastos que habías tenido y claro, te faltaron 500 coronas y te las daban, ientiendes? era impresionante. O sea, no te las daban, pero te pagaban la cuenta, eso de adonde (con gesto de impresión)... Si la parte anímica uno la tenía aportillada, bueno, por lo menos la parte material estuviera tranquila, porque tú estás con todas las cosas caóticas, no puedes mejorar de nada ¿entiendes? El alma no se cura si estás con la cuenta del teléfono... y la 
comida ¿̇me entiendes? Tú tienes que tener cierta paz para poder trabajar lo de adentro también. (Segundo participante)

El relato del segundo participante describe la ayuda que el Estado sueco proporcionaba a los exiliados durante su inserción en la sociedad, la que en cierta medida apuntaba a subsidiar las eventualidades que se presentaban en la vida de estas personas. A la vez, cuando un exiliado salía de los campamentos de refugiados, existía la posibilidad de optar a préstamos para pagar un arriendo como señala el tercer participante o para pagar los estudios como señala el segundo participante:

Ese préstamo digamos, teníamos una cantidad de años para devolverlo y el arriendo los primeros seis meses ellos lo pagaban, el Estado sueco, el Estado sueco, Estado sueco lo financiaba, con ayuda de por medio de la ayuda social que le dan a cualquier sueco. (Tercer participante)

Eso duraba mientras te pudieras ubicar, o sea, yo me puse a estudiar de inmediato, así que cuando tú estudias, tú puedes pedir un préstamo de estudios. Este tiempo terminé, no recuerdo cuánto tiempo me estuvieron ayudando, no me acuerdo, pero yo no tuve un apremio de decir, si yo no termino en diciembre no voy a tener o poder comer en enero, no había una angustia económica. No éramos ricos, pero no teníamos ninguna carencia. (Segundo participante)

En las palabras de estos participantes se evidencia que este tipo de ayuda facilitaba su inserción en la sociedad sueca y les daba tranquilidad para comenzar una nueva vida. Por otra parte, hubo personas que luego de recibir la ayuda de alquiler y de estudios, tuvieron crisis asociadas a la experiencia vivida antes de dejar Chile. En el siguiente relato, la novena participante comenta que la ayuda cesó producto de una crisis y que debió comenzar a trabajar para mantenerse en Suecia:

Llegué en noviembre, en enero me fui a vivir sola y entré a estudiar sueco, estudié cuatro meses, después hice una crisis y fui a parar al hospital. Después de un par de meses no seguí estudiando sueco, hasta entonces tenía las ayudas del bienestar social que eran suficiente; yo era sola, no tenía gastos y era bastante espartana comparada con ahora, con todo lo que me daban, yo creía que era demasiado. Después me puse a trabajar en agosto del año 78, me puse a trabajar en un hospital cuidando gente con discapacidad muy grave. (Novena participante)

El apoyo del Estado sueco también se evidenció cuando los exiliados comenzaron a organizarse socialmente. El relato del tercer participante comenta cómo se apoyó la organización en las escuelas y la enseñanza del idioma materno, situación que está presente hasta el día de hoy:

Nosotros digamos nos organizamos con... en cuestiones culturales con los niños, viste. Mi mujer con otra organizaron la escuela, las escuelas de 
dos idiomas, claro, o sea, español y sueco y que existieron hasta hace 15 años atrás. Eso recibía apoyo del Gobierno ¿viste? en la escuela inclusive se habla, mis nietos hasta el día de hoy piden español y tienen que darle español, eso es ley de Gobierno, lengua materna.... ehh nosotros nos juntamos para cuando hacían fiestas grandes los suecos, ahora como el verano, nosotros nos fuimos, la empanada fue la herramienta que llegó a los suecos para ser solidaridad con los suecos, nosotros le vendimos empanadas a todos los suecos, nosotros hacíamos empanadas hueón y me acuerdo en Holma y las llevábamos en bicicleta hasta por todos lados en esas huevas donde venden helado en Chile, en eso llevábamos las empanadas y salían las empanadas del horno y a vender empanadas, a vender empanadas. Siempre hemos dicho, debiéramos haber hecho un monumento a la empanada, porque fue la herramienta, el instrumento para integrarnos a la sociedad y a la política sueca, no llegamos de otra manera. (Tercer participante)

A diferencia de los otros relatos, en este fragmento de la entrevista el tercer participante explica que si bien la ayuda del Gobierno fue importante en la inserción y adaptación de la vida de los exiliados en Suecia, el conglomerado chileno comenzó a organizarse para recaudar fondos y emprender acciones de solidaridad que no solamente les permitió integrarse a la sociedad sueca, sino también ingresar a la política de ese país. Es importante destacar que las acciones de solidaridad fue una estrategia de asociación política que les permitió a los exiliados organizarse en Suecia. Después de todo, si habían salido de Chile por un compromiso de participación de esta índole, resulta casi natural que su primera forma de organización tuviera esta característica. En la segunda categoría del exilio se revisa cómo los exiliados realizaban acciones de solidaridad para mantener su participación y vida política en Suecia.

\section{b) La vida política a través de acciones solidarias}

La literatura respalda que los chilenos exiliados se organizaron en los países donde llegaron y promovieron actividades solidarias que servían para recaudar fondos y entregar información que iba dirigida a denunciar los crímenes a los derechos humanos en Chile. Los exiliados residentes en Suecia no fueron la excepción y emprendieron una lucha contra la dictadura en Chile mediante conferencias, manifestaciones, actos de solidaridad, conciertos y exposiciones teatrales. Sin embargo, para los exiliados fue difícil planificar una estrategia de trabajo, dada la lejanía y los problemas de comunicación con sus pares que estaban en Chile. Esto motivó que volcaran sus esfuerzos en actividades solidarias para aprovechar la instancia y trabajar en acciones políticas.

De este modo, las acciones de solidaridad eran actividades que permitían a los exiliados mantener viva la organización política, despejar la mente y reunir fondos para continuar luchando contra la dictadura a distancia. En esta etapa del exilio se veían a sí mismos como un apoyo a la resistencia para derrocar a 
la dictadura (Bolzman, 1994). En el relato que sigue del tercer participante, se extraen las características de esta forma de solidaridad a través de la venta de un alimento de masa y carne típico chileno, la empanada, que causó revuelo entre la población sueca y les permitió realizar "mucha solidaridad":

Llegamos vendiendo una cosa que se llama Kavring, bandera chilena y comidas chilenas, empaná ${ }^{1}$ ipiroger! ipiroger! (haciendo un gesto con las manos en la boca y elevando la cabeza como si gritara). La cola de gente, todos decían qué rica, qué rica, qué rica, después de cada fiesta, el 01 de mayo, en la fiesta de la izquierda... la empanada fue como te digo, la cosa que nos llevó a hacer mucha, mucha solidaridad, vendimos muchas empanadas.

Ese era el puntal, el trabajo político que se hacía en Suecia, la solidaridad con el pueblo chileno, a veces fiesta, mercado de las pulgas para mandar dinero a los presos políticos, a las organizaciones políticas, organizaciones de solidaridad que son el Comité Salvador Allende, ehh el Chilekommittén aquí en Malmö, el Chilekommittén y... luego digamos, los partidos políticos. (Tercer participante)

La ciudadanía local también emprendió actividades solidarias para contribuir en la causa chilena, lo que estaría fundamentado en que la sociedad sueca comenzó a mostrar un interés por la realidad de América Latina luego de la revolución cubana (Camacho, 2011). En el fragmento que se presenta a continuación, se aprecia como los suecos mostraban interés por conocer lo vivido por los exiliados, abriendo la puerta para que los chilenos desarrollaran amistades y entraran al mundo sueco:

Había un movimiento de solidaridad muy fuerte con Chile, entonces entre ahí, alguien me invitó a dar una charla con interprete, me preguntó, me encontró en la calle, me preguntó de dónde era y comenzamos a conversar. Me preguntó dónde vivía, ellos vivían cerca, comenzamos, era un colectivo de izquierda, de solidaridad con Chile y me empezaron a invitar a su casa y me preguntaron si yo quería dar una charla de la situación que había en Chile, era el Chilekommittén y ellos vendían arpilleras que la vicaría mandaba y me incorporé ahí, entonces hice mucha amistad con suecos. (Novena participante)

Analizando en conjunto los fragmentos de esta categoría, no se debe olvidar que el compromiso, el activismo y sus prácticas políticas enmarcaron las razones por las que estas personas tuvieron que dejar Chile, por lo que no extraña que su asociacionismo político en Suecia se desarrollara mediante actividades con características similares. A la vez, estas actividades solidarias daban vida a la forma que tenían los exiliados de luchar contra la dictadura, de luchar por su retorno, el que tenía un valor simbólico de que todo volvería a ser como antes. La situación descrita estaba determinada porque los

1 La empanada es una comida típica chilena y su traducción en sueco es "Piroger". 
chilenos vivieron durante años con las maletas hechas, esperando la primera oportunidad para volver a su país, dispuestos a subir al primer avión hacia Chile si algo indicaba que esto era posible (Pérez, 1996). De esta manera, las intenciones de retornar se expresaban en las acciones de solidaridad que buscaban contribuir al derrocamiento de la dictadura.

La realidad descrita se vivió mientras los exiliados esperaban el fin del régimen y planeaban su retorno a Chile, pero contrario a lo que ellos pensaban, la dictadura se consolidó en el poder y tuvieron que adaptar su proyecto migratorio de un exilio provisorio a un asentamiento permanente. Al percatarse que su estadía en el país que los acogió sería más larga de lo esperado, empezaron a cuestionarse cuál era su lugar y el de su familia en el país de acogida, por lo que al igual que otros refugiados chilenos en Europa, comienzan a desempacar las maletas y a desarrollar proyectos personales o familiares para integrarse (Bolzman, 1994).

En los primeros cinco años de la década 1980 los exiliados sufren distintos quiebres en las relaciones sociales con sus compatriotas, lo que era la consecuencia del esfuerzo y tensiones constantes por organizarse en la sociedad de destino. Entre los motivos de esta ruptura se encuentra la frustración por la imposibilidad de concretar el sueño del retorno. Con la colectividad quebrada desde adentro, los exiliados fueron ingresando a las distintas estructuras de la sociedad sueca. Llegado el año 1985 surge la primera oportunidad para retornar a Chile, sin embargo y contra todo pronóstico, se estima que un poco más del $50 \%$ de las personas que tomaron esta opción, volvieron a Suecia en menos de cuatro años (Bengtsson et alii, 2005). Se presume que la principal razón de este retorno fallido, es que en Chile todavía imperaba el régimen militar.

En el año 1988, tras años de presión internacional y un arduo trabajo político de la oposición, se realizó el plebiscito para determinar si el régimen militar continuaba hasta el año 1997 o si era necesario llamar a elecciones. Con el triunfo del "NO" se daba paso al primer índice de democracia en Chile en años y se prepararon las elecciones presidenciales de diciembre de 1989. En la oportunidad triunfó el candidato de la Concertación de Partidos de la Democracia, el señor Patricio Aylwin, quien asumió la presidencia de Chile en marzo de 1990. Este hecho que daba por finalizada la dictadura militar, llevó a que la decisión de permanecer o retornar, fuera una opción individual y no de la contingencia sociopolítica (Askeland, Sønneland, 2011). Así, de las 27.000 personas que vivían en Suecia en el año 1992, solamente 790 retornaron a Chile (Camacho, 2011). El bajo retorno pudo estar determinado por la integración de la comunidad en Suecia o por una buena situación económica, no obstante, algunas de las familias que volvieron a Chile tuvieron que afrontar que sus hijos no se identificaron con la cultura y la sociedad chilena, motivo 
por el que decidieron volver al país escandinavo (Camacho, 2011). En este sentido, hubo varios motivos para que los exiliados permanecieran en la sociedad que los había recibido, destacando el rol que tuvo el surgimiento de nuevas identidades, proyectos personales y proyectos familiares que estas personas jamás se habían imaginado (Bolzman, 1993).

Durante el exilio los chilenos construyeron su vida soñando el retorno, ahora debían distinguir entre lo personal, lo familiar, lo real y lo que pasará a ser un mito. Es así que el retorno a la democracia en Chile daba fin a las razones del exilio de muchos chilenos y dio inicio a un proceso de decisión impensado y que no había sido contemplado hasta el momento iretornar a Chile o permanecer en Suecia? A pesar de que los exiliados llevaban años en la sociedad de acogida, no estaban preparados para afrontar este dilema que nunca habían previsto. Esta etapa se denomina post-exilio y se vive desde el fin de la dictadura hasta la actualidad.

\section{Post exilio}

El post-exilio tuvo distintas formas de expresión, así como distintas formas de abordarlo. La principal característica de este período fue la manera en que los exiliados volvieron a definir su presencia en la sociedad de acogida (Bolzman, 1993). En un comienzo este período estuvo determinado por el cambio del modo de vida que iba desde la preparación para el retorno, al cómo afrontar la permanencia personal y familiar en Suecia.

Esta etapa que comenzó con el fin de la dictadura, se caracterizó por la reconfiguración del proyecto de vida de exiliado a un proyecto migratorio marcado por el desencuentro con la sociedad de origen y la sociedad de acogida; un laberinto del cual no todos pudieron salir airosos. Quienes se quedaron en Suecia vieron cómo empezó a cambiar la percepción que había de ellos en la sociedad, dado que ya no eran vistos como exiliados, sino como inmigrantes. El siguiente apartado aborda cómo los chilenos vivieron su post-exilio en Malmö y las principales características de este período.

\section{a) De exiliado a inmigrante}

La presente categoría de análisis muestra la primera consecuencia del post-exilio, el cambio de sentirse exiliados a inmigrantes, en una sociedad que siempre los valoró y respeto por ser distintos a las otras personas que llegaban a Suecia, es decir, por ser refugiados políticos. El relato del tercer participante describe cómo su status social era respetado en Suecia cuando llegó por su condición de refugiado, situación que cambió cuando adquirió la condición social de inmigrante:

Nosotros ya no somos refugiados políticos ¿ya? Porque desde que se terminó la dictadura, nosotros... ¿entendí? Los que quisieron se 
quedaron, otros se marcharon, otros hicieron arreglos con el Gobierno chileno, Gobierno sueco, para su retiro y ver el retorno de los chilenos de aquí para sus pensiones.

Hoy somos inmigrantes, hoy estamos en esa, en esa calidad ¿viste? pero antes en un principio fuimos refugiados políticos y como refugiados políticos nosotros teníamos una cantidad maomeno impresionante de derechos que son igual a los que tenían los suecos. (Tercer participante)

Porque hay una cosa que hace la diferencia, cuando tú migras, una cosa es el inmigrante, otra cosa es el refugiado. El inmigrante puede volver cuando él quiera y lo decide él de migrar, el refugiado no, porque no le queda otra salida inosotros no elegimos Suecia! nosotros habríamos, lo más lindo habría sido quedarnos en Chile. (Cuarta participante)

Al analizar este fragmento se obtiene que con el fin de la dictadura se pierde el status sociopolítico de refugiado, puesto que desapareció la razón que motivó su exilio. Posterior a este hecho, la decisión de quedarse fue personal y no política. La forma de abordar el post-exilio en Europa varió según el capital cultural de las personas, en el caso de los chilenos en Malmö, se configuró una construcción social para autodefinirse como refugiados políticos que les otorga una imagen respetada en comparación a los otros chilenos que llegaron a Suecia a partir de 1985:

Los que llegaban acá tenían cierta noción política, que salían por ser perseguidos, pero también no te olvides de una cosa muy importante, a mitad de los 80's, la mayoría que llegaron, comenzaron a llegar mucha gente con problemas económicos y con problemas sociales en Chile, que llegaron acá a buscar la vida y también muchos a desprestigiar a los chilenos, porque llegó de todo, porque la gente llegaba por problemas políticos, por principios de lucha de clase, no de luchas por la vida, yo lucho y salgo. No eran problemas sociales de vida que no tenías que echarte a la boca, porque muchos en Chile ya estaban quemados por sus problemas de criminalidad, llegó mucha gente de esa después de la mitad de los 80's. Cuando nosotros, cuando decimos no llegamos después del 85, nosotros somos refugiados políticos; no importa, suena mal, pero ponelo si lo vas a poner. (Cuarta participante)

La gente que Ilegaba después nunca llegaban solos, siempre tenían una conexión, no llegaban solos. Ya no tiene mucho que ver con política, sino que con los problemas económicos que contrae una dictadura en Chile o gente que digamos que busca mejores oportunidades de vida ¿no? Y hoy día encontramos que aquí en Malmö deben haber, no sé poh, digamos... no sé si me quedo bajo si digo 4.000 ó 5.000 chilenos ¿es una suma bastante grande no? (Tercer participante)

Como se aprecia en estos relatos, los exiliados comienzan a separarse de los chilenos que Ilegaron por motivos económicos. Un punto importante a considerar es que a pesar de que tuvieron la oportunidad de retornar a Chile, ellos continúan sintiéndose y definiéndose como refugiados políticos, 
separándose de inmigrantes que tienen la misma procedencia, pero que llegaron por otros motivos. En el relato que sigue se observa que la disociación entre exiliado e inmigrante se consolida como un mecanismo de defensa, representándose como una autovaloración por el prestigio de los exiliados y el desprestigio alcanzado por los inmigrantes económicos chilenos que llegaron a Suecia en la década de 1980. A la vez, plantean una diferencia con los chilenos que llegaron después y justifican su posición en Suecia, pero a diferencia de los relatos anteriores, en las palabras de la primera participante se le asignan características negativas al exogrupo y características positivas al endogrupo:

Cuando hablaban no nos entendemos porque ellos no han experimentado lo que yo he experimentado y se trata más de economía y de eh eh socioeconómico, razones socioeconómicas. Claro, si eres campesino, lo fuiste y nunca estudiaste y tienes más dificultades en integrarte, estás destinado a pasarlo mal, peor que nosotros que nos adaptamos rápidamente. Obvio que es un factor importante cuando uno llega a un país, lo que le pasa a todos los grupos de extranjeros ime entiendes? El salto no fue tan grande para nosotros, llegamos acá y pudimos seguir la vida no igual, pero bastante similar en el fondo, no fue chocante. (Primera participante)

Lo expuesto en este relato podría considerarse como la justificación del sentido de pertenencia grupal para establecer una diferencia que les permite conservar su status privilegiado y con el prestigio social que es reconocido por la sociedad sueca. De este modo, la construcción de la identidad es el producto de la interacción con la sociedad receptora y con personas de la misma nacionalidad, pero que tuvieron una razón distinta para emprender el desplazamiento. Respecto a esto, es habitual que personas con diferente origen étnico sean alentadas a mantener las características culturales que los representan, ya que les otorga un prestigio particular en la sociedad de acogida (Silvers, 1965). Esta distinción entre los chilenos políticos y los chilenos económicos ha estigmatizado a los inmigrantes chilenos según su motivo de llegada a Suecia. En el siguiente relato se manifiesta una construcción social categórica que responde a los requerimientos de la vida diaria en la sociedad de acogida, distinguiendo entre los chilenos buenos y malos, lo cual está determinado por la fecha en que Ilegaron a Suecia y la categoría social adquirida de económicos o políticos.

Cuando la gente dice, no, pero tú eres uno de esos especial, tú no eres como un extranjero, tú eres un extranjero bueno, de los buenos. Hemos escuchado los económicos, los políticos, ustedes son de los que llegaron primero, son políticos, culturales. (Primera participante)

En esta categoría se analizó cómo los exiliados justifican su construcción social en Suecia luego de que el fin de la dictadura militar en Chile llevara a que 
desapareciera el motivo que originó su exilio. Como ellos lo definen, dejaron de ser refugiados y empezaron a verse socialmente como inmigrantes. Sin embargo, ellos se identifican como "inmigrantes políticos" que se asentaron en Suecia en la década de 1970 como refugiados y se diferencian constantemente de los inmigrantes económicos que llegaron en la década de 1980.

La característica principal del post-exilio es que el anhelado retorno se convierte en un mito para estas personas, por lo que cambian su proyecto de retorno y ejecutan acciones para continuar sus estudios, conseguir un trabajo con mayor prestigio social o centrar su preocupación en el aspecto que más descuidaron durante la lucha por el retorno, su familia. Por esta razón, cuando los exiliados comenzaron a preguntarse cuál era su lugar en el país de acogida, la familia se erigió como el pilar fundamental para reestructurar su proyecto de retorno como exiliado a un proyecto migratorio y así justificar su permanencia en Suecia. En esta línea, el fundamento principal de su estadía es su rol en la crianza de los nietos, lo que analizado desde la toma de conciencia que tuvieron al momento del post-exilio, se aprecia como un acto de retribución hacia sus hijos e hijas por el tiempo que no les dedicaron por su activa labor política llevada en Chile y luego en su exilio. Por este motivo, gran parte de la influencia familiar que adoptó el proyecto migratorio de estos exiliados estuvo determinada por las raíces que echaron sus descendientes y que emocionalmente les impidió dejar el país que los recibió.

\section{Discusión}

Durante la dictadura militar que vivió Chile entre los años 1973 y 1990, hubo una fuerte persecución a las personas que eran partidarias del Gobierno caído o que simplemente eran contrarias al régimen dictatorial. Miles de personas abandonaron el país hacia diferentes destinos por motivos de seguridad. Los chilenos que llegaron a Suecia se adaptaron a una sociedad que entendía su lucha social, sin embargo, estos exiliados vivieron una serie de fenómenos derivados de los cambios del contexto socio-político de Chile, los que dividieron la vida de estas personas en el exilio y el post-exilio.

Durante la etapa del exilio los participantes describieron un alto nivel de participación en acciones de solidaridad, las que les permitieron articular una red para enviar recursos a Chile y vivir en conjunto el sueño del retorno. Estas actividades que se estructuraban en un marco solidario, también hicieron factible estructurar una forma de organización política y revivir en cierta medida las prácticas sociopolíticas que tenían en Chile. Al mismo tiempo, estos actos ayudaban a que los exiliados justificaran que tenían el derecho de estar en la sociedad que los recibió (Bolzman, 1994). 
El retorno a la democracia en Chile causó un cisma en la vida de estas personas, puesto que llegó a su fin su status de exiliado en Suecia y pasaron de ser refugiados a inmigrantes. Tras este hecho y en la mayoría de los casos, dejaron su vida de exiliados políticos y se adentraron en los caminos del post-exilio, etapa marcada por la reconstrucción personal y familiar. Estos factores jugaron en contra para que los chilenos retornasen a Chile, ya que en este caso, volver a su sociedad de origen no significó lo mismo que regresar a casa. Cuando los exiliados se percatan que su estadía en Suecia sería por más tiempo del que habían pensado, comienza una nueva forma de definir su identidad de exiliado para no perder su status privilegiado de extranjero en Suecia. Es así que se autodenominaron como inmigrantes políticos para diferenciarse de los inmigrantes chilenos que llegaron por motivos económicos. La situación descrita es similar al caso de los exiliados chilenos en Suiza, quienes inconscientemente redefinieron su identidad colectiva como inmigrantes políticos para reforzar una imagen positiva de sí mismos y a la vez, amortiguar el estigma social que tenían en la sociedad de acogida (Bolzman, 1994).

El caso de los exiliados chilenos en Malmö expone una realidad poco estudiada, mostrando cómo después de tantos años sigue en su memoria la forma en que se adaptaron en Suecia y construyeron su vida en el post-exilio hasta el día de hoy. Quienes decidieron quedarse vieron cambiar su identidad y la manera de interpretarla, específicamente en el cambio de la construcción social de refugiado a inmigrante. De esta suerte, la percepción que le otorgan a su identidad se ve influenciada por la interacción sostenida con su entorno, sus compatriotas, su familia y el país de origen.

En Chile están por cumplirse 30 años desde que se acabó la dictadura, no obstante, hasta el día de hoy se evidencian secuelas de este período en la sociedad chilena y los chilenos que tuvieron que exiliarse y no retornaron al país. El caso de los chilenos exiliados en Malmö deja la experiencia que las organizaciones de la sociedad civil y el Estado deben trabajar con los refugiados en la preparación psicosocial no solamente en la llegada, sino también para afrontar las decisiones de cómo avanza su inserción en la sociedad y afrontar los cambios sociopolíticos de su país de origen. El presente estudio aporta sobre los posibles dilemas y desafíos que pueden enfrentar los refugiados políticos después de un largo tiempo en la sociedad de acogida. A futuro, será importante ahondar cómo estas formas de reconstruir la identidad y afrontar el exilio, repercuten en la familia de los refugiados.

\section{Referencias}

ASKELAND, Gurid; SØNNELAND, Anne. You will never again be a Chilean like the others: From diaspora to diasporic practices among Chilean refugees returning 
from exile. Journal of Comparative Social Work, v. 6, n. 1, p. 1-18, 2011.

BENGTSSON, Tommy; LUNDH, Christer; SCOTT, Kirk. From Boom to Bust. The Economic Integration of Immigrants in Post War Sweden. In: ZIMMERMANN, Klaus (ed.). European Migration: What Do We Know? Oxford: Oxford University Press, 2005, p. 15-58.

BOLZMAN, Claudio. Los Exiliados del Cono Sur dos décadas más tarde. Nueva Sociedad, n. 127, p. 126-135, 1993.

BOLZMAN, Claudio. Stages and modes of incorporation of exiles in Switzerland: The example of Chilean refugees. Innovation: The European Journal of Social Science Research, v. 7, n. 3, p. 321-333, 1994.

BOLZMAN, Claudio. Sociologie de l'exil: une aproche dinamique. Zurich: Seismo, 1996.

CAMACHO, Fernando. Una Vida para Chile: la solidaridad y la comunidad chilena en Suecia 1970-2010. Chile: LOM, 2011.

CAMACHO, Fernando. El golpe de Estado en Chile y la reacción de Suecia. Cuadernos Americanos, v. 4, n. 154, p. 203-238, 2015.

DOORN, Elsa. El exilio argentino en Suecia: 1973-1983. In: I Jornadas de Trabajo sobre Exilios Políticos del Cono Sur en el siglo XX. La Plata, Argentina, 26, 27 y 28 de septiembre de 2012.

GARCÍA, Yvette. El trabajo militante del exilio chileno en Francia: Contextualización, descripción, micro-medios de comunicación y sus impactos. Revista IZQUIERDAS, n. 17, p. 81-92, 2013.

INE; DICEOEX. Chilenos en el exterior: Dónde viven, cuántos son y qué hacen los chilenos en el exterior. 2015. Disponible en: <http://www.chilesomostodos. gov.cl/wp/wp-content/uploads/2015/07/Registro-de-Chilenos-en-elExterior-2003-2004.pdf>. Acceso en: 17.03.2018.

MARTíNEZ, Jorge; SOFFIA, Magdalena; CUBIDES, José; BORTOLOTTO, Idenilso. Migración Internacional en Chile: tendencias, políticas, normas y participación de la sociedad civil. In: CHIARELLO, Mario (coord.). Las políticas públicas sobre migraciones y la sociedad civil en América Latina: Los casos de Bolivia, Chile, Paraguay y Perú. Santiago de Chile: Scalabrini International Migration Network Inc., 2013, p. 117-242.

MONTESINO, Norma. Movilidades Humanas e Intervención Social. In: BERRÍOS, José; BORTOLOTTO, Idenilso (eds.). Migración e Interculturalidad: perspectivas contemporáneas en el abordaje de la movilidad humana. Chile: San Pablo, 2017, p. 275-304.

MOSSELSON, Jacqueline. Roots \& Routes: A re-imagining of refugee identity constructions and the implications for schooling. Current Issues in Comparative Education, v. 9, n. 1, p. 20-29, 2006.

MUNGOI, Dulce. Ressignificando identidades: um estudo antropológico sobre experiências migratórias dos estudantes africanos no Brasil. REMHU, Revista Interdisciplinar da Mobilidade Humana, v. 20, n. 38, p. 125-139, 2012. 
PÉREZ, Enrique. La búsqueda interminable: Diario de un exiliado politico chileno en Suecia. Santiago de Chile: Mosquito, 1996.

PINTO, Candelaria. Exilio chileno: 1973-1989: Consecuencias del exilio, cómo se vive el exilio, producción artístico-cultural del exilio, Memoria de hijos de exiliados retornados de Francia. In: I Jornadas de Trabajo sobre Exilios Políticos del Cono Sur en el siglo XX. La Plata, Argentina, 26, 27 y 28 de septiembre de 2012.

REBOLLEDO, Loreto. Memorias del desarraigo: Testimonios de exilio y retorno de hombres y mujeres de Chile. Santiago de Chile: Catalonia, 2006.

SILVERS, Ronald. Structure and Values in the Explanation of Acculturation Rates. The British Journal of Sociology, v. 16, n. 1, p. 68-79, 1965.

SORIANO-MIRAS, Rosa. Inmigración e identidad social: similitudes y diferencias en el proyecto migratorio de mexicanas a EEUU y mujeres marroquíes a España. Migraciones, n. 23, p. 117-150, 2008. 